\title{
Prevalence of Vitamin D Deficiency in a Young Adult With Acute Spinal Cord Injury
}

Shah Waliullah ${ }^{1}$, Deepak Kumar ${ }^{1}$, Dharmendra Kumar ${ }^{1}$, Prakash G. Tewari ${ }^{1}$, Vineet Kumar ${ }^{2}$, Rajeshwar N. Srivastava ${ }^{1}$

1. Department of Orthopaedic Surgery, King George's Medical University, Lucknow, IND 2. Department of Orthopaedic Surgery, Dr. Ram Manohar Lohia Institute of Medical Sciences, Lucknow, IND

Corresponding author: Vineet Kumar, mailsforvineet@gmail.com

\begin{abstract}
Introduction: Vitamin D deficiency has been implicated as an etiologic factor responsible for osteoporosis and various skeletal and extra-skeletal issues in spinal cord injury patients. There is a dearth of publications regarding the prevalence of vitamin D deficiency in acute spinal cord injury (ASCI) patients, thus it becomes imperative to study the status of vitamin D in ASCI cases to make an early diagnosis and start treatment for osteoporosis. Apart from this, we also planned to evaluate other factors associated with vitamin D deficiency in our subset of patients.
\end{abstract}

Material and methods: This cross-sectional cohort study included patients with acute thoracolumbar spinal cord injury patients admitted to a tertiary trauma centre between July 2019 and July 2020. Patients were assessed clinically and classified as per the American Spinal Cord Injury Association (ASIA) scale. Demographic details along with the mode of trauma and duration of injury were noted. Serum $25(\mathrm{OH})$ vitamin D3 levels were measured by chemiluminescence immunoassay. Depending upon serum 25(OH) vitamin D3 level, patients were classified into vitamin D deficient with serum level less than $20 \mathrm{ng} / \mathrm{ml}$, vitamin D insufficient with serum level between $21-29 \mathrm{ng} / \mathrm{ml}$ and vitamin D sufficient with serum level greater than $30 \mathrm{ng} / \mathrm{ml}$.

Results: Mean vitamin D level in 85 ASCI subjects (mean age $30.82 \pm 6.77$ years, 60 males) was $20.56 \pm 11.22$ $\mathrm{ng} / \mathrm{ml}$. Fifty subjects (58.82\%) were vitamin D deficient, 15 subjects (17.64\%) were vitamin D insufficient and the rest $(n=20,23.52 \%)$ were vitamin $D$ sufficient. There was no significant difference in vitamin D levels as per gender, age, mode of trauma, type of injury and injury location. Patients admitted on the fifth day of injury had maximum vitamin D levels (mean $25.7143 \pm 8.32 \mathrm{ng} / \mathrm{ml}$ ), but it was also insignificant. The mean vitamin D level of subjects with samples taken during the summer season was significantly higher as compared to the winter season ( $\mathrm{p}$ value $<.05$ ).

Conclusion: Vitamin D deficiency is widely prevalent in ASCI patients at admission to the trauma centre. Seventy-six percent of patients had vitamin D levels below $30 \mathrm{ng} / \mathrm{ml}$ in our study. Routine measurement of $25(\mathrm{OH})$ vitamin D3 levels at the time of admission is recommended for early diagnosis of vitamin D deficiency. Early treatment will be helpful in the prevention of osteoporosis and its long-term related consequences.

Review began 03/02/2021 Review ended 03/09/2021 Published 03/09/2021

\section{() Copyright 2021}

Waliullah et al. This is an open access article distributed under the terms of the Creative Commons Attribution License CC-BY 4.0., which permits unrestricted use, distribution, and reproduction in any medium, provided the original author and source are credited.
Categories: Medical Education, Orthopedics, Trauma

Keywords: vitamin-d deficiency, acute spinal cord injury, osteoporosis

\section{Introduction}

Vitamin D is a steroid hormone and is synthesized in the skin or ingested through diet and converted into the active form after two hydroxylations, firstly at the liver and then the kidney. Its active metabolite binds to the nuclear vitamin D receptor (VDR) and carries out various genomic activities. Vitamin D has been associated with modifying the expression of several genes associated with axogenesis, myelination, neuronal-cell differentiation and repair [1,2].

Spinal cord trauma is a devastating injury, and its sequelae range from normal neurology to complete paralysis and even death. Patients with normal neurology gain ambulation in due time depending upon injury severity; however, patients with incomplete and complete spine injury face prolonged immobilization and several problems pertaining to immobilization. Because of immobilization and disturbed endocrinal axis, osteoporosis and consequent fractures are challenging threats to manage in these patients. Vitamin D deficiency has been implicated as an etiologic factor responsible for osteoporosis and various skeletal and extra-skeletal issues in spinal cord injury patients [3-7].

Several reports have highlighted the presence of vitamin D deficiency in chronic spinal cord injury patients [5-7]. There are very few reports regarding the prevalence of vitamin D deficiency in acute spinal cord injury (ASCI) patients, thus it becomes imperative to study the status of vitamin D in ASCI as it will help to know 
whether spinal trauma is an initiating factor for vitamin D deficiency, or if they are previously vitamin D deficient before the trauma $[8,9]$. Moreover, it will help to start early treatment in deficient cases to prevent future problems. With this study, we also want to evaluate various factors associated with vitamin D deficiency in our region's spinal cord injury patients.

\section{Materials And Methods}

This cross-sectional cohort study included acute thoracolumbar spinal cord injury patients admitted to our tertiary trauma centre from July 2019 to July 2020. Institutional ethical clearance (IEC number: 95th ECM II $\mathrm{A} / \mathrm{P} 5$ ) was taken before the initiation of the study. The data was retrieved from the online records of the institutional database. Data of all the cases admitted between the said period suffering from traumatic SCI within a week of injury and satisfying our inclusion and exclusion criteria were selected for the study. All the cases of traumatic thoraco-lumbar (D1-L5) spine injury presenting to us within one week of injury were recruited in the study. The data was recorded for radiological and clinical findings. The clinical findings were recorded as per the American Spinal Cord Injury Association (ASIA) scale [10] and divided into three categories: ASIA A complete injury, ASIA B, ASIA C, ASIA D as incomplete injury and ASIA E as neurologically intact cases. Demographic details, along with the mode of trauma and duration of injury, were noted. Patients with injury more than seven days were excluded. Any patient with previous treatment for vitamin D deficiency or taking medications affecting vitamin D metabolism or suffering from malignancy, endocrinal disorder, hepatic disorder, renal disorder, or a gastrointestinal disorder affecting calcium and vitamin D metabolism, were excluded from the study. Serum $25(\mathrm{OH})$ vitamin D3 levels as measured by chemiluminescence immunoassay were recorded. Vitamin D levels from the samples taken at the time of admission and the season during which the sample was taken were also documented; whether summer (March to August) or winter (September to February). Depending upon serum 25(OH) vitamin D3 levels, the patients were classified as vitamin D deficient (serum level less than $20 \mathrm{ng} / \mathrm{ml}$ ), vitamin $\mathrm{D}$ insufficient (serum level between $21-29 \mathrm{ng} / \mathrm{ml}$ ) and vitamin D sufficient (serum level greater than $30 \mathrm{ng} / \mathrm{ml}$ ) [11].

\section{Statistical analysis}

All statistical analyses were performed by Statistical Package for Social Sciences (SPSS) version 16.0 (SPSS Inc., Chicago, IL, USA) and Graph Pad Prism version 5 (GraphPad Software, La Jolla, CA, USA). The quantitative data were analyzed using the Mann Whitney U test/t-test, and Kruskal Wallis/analysis of variance (ANOVA) was used to compare the different groups of variables. $P$ value $<0.05$ was considered to be statistically significant.

\section{Results}

Mean vitamin D level in 85 ASCI subjects (mean age $30.82 \pm 6.77$ years, 60 males) was $20.56 \pm 11.22 \mathrm{ng} / \mathrm{ml}$. Fifty subjects (58.82\%) were vitamin D deficient, 15 subjects (17.64\%) were vitamin D insufficient and the remaining 20 subjects (23.52\%) were vitamin D sufficient (Figure 1, Table 1). 


\section{Cureus}

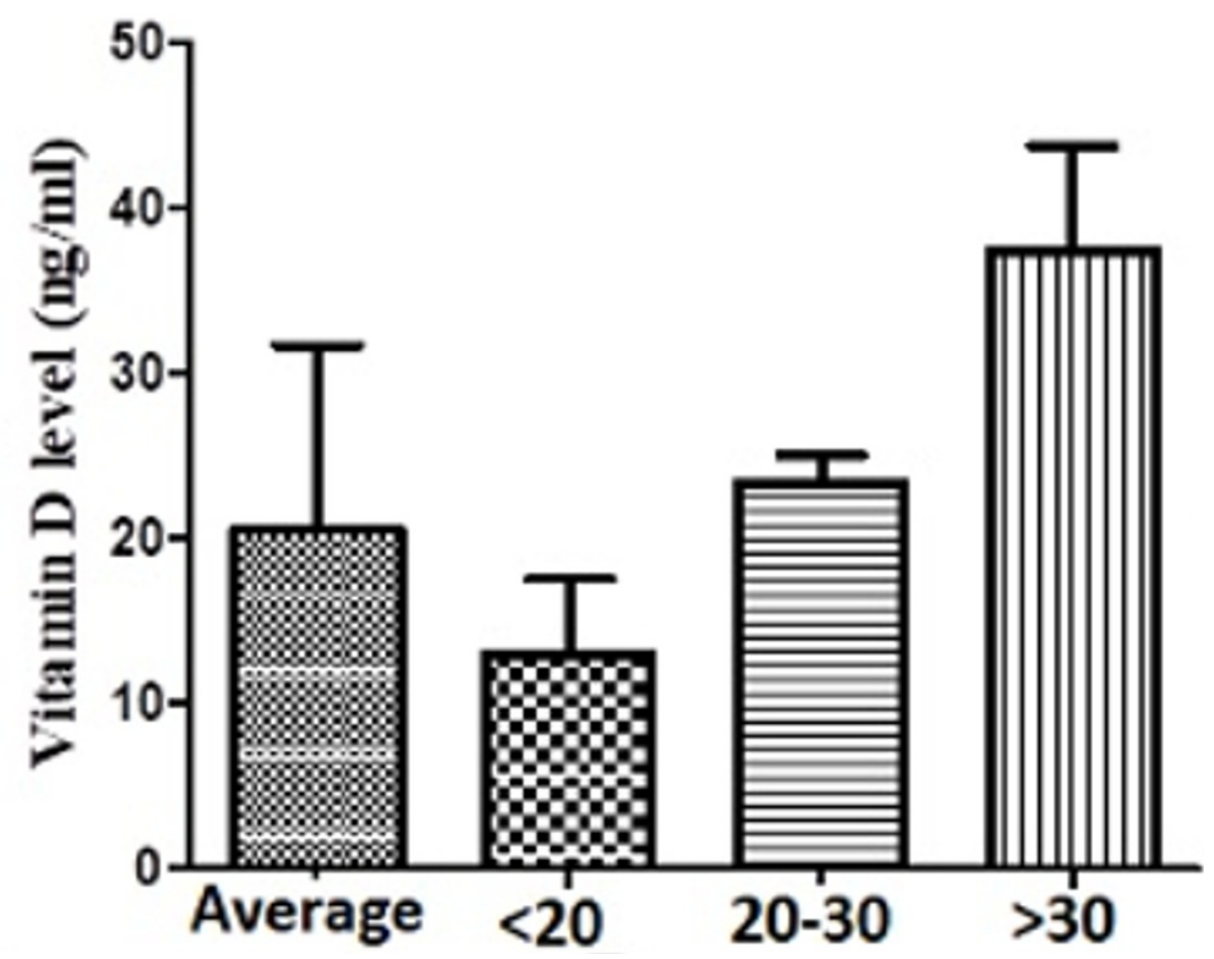

FIGURE 1: Vitamin D levels in the study population

\begin{tabular}{|c|c|c|c|c|}
\hline & Vitamin D levels ( $n=85$ ) (in ng/ml) & $<20(n=50)$ (in ng/ml) & $21-30$ (n=15) (in ng/ml) & $>30(n=20)$ (in ng/ml) \\
\hline Mean & 20.56 & 12.95 & 23.35 & 37.48 \\
\hline Std. Deviation & 11.22 & 4.62 & 1.68 & 6.30 \\
\hline
\end{tabular}

TABLE 1: Vitamin D levels in the study population

There were no significant differences in vitamin D levels as per gender, age distribution, mode of trauma or native origin (Table 2). There was no association between the type of injury and the level of injury (Table 2). 


\section{Cureus}

\begin{tabular}{|c|c|c|c|c|}
\hline & \multirow[b]{2}{*}{$\mathrm{N}(\%)$} & \multicolumn{2}{|c|}{ 25(OH) Vitamin D levels ng/ml } & \multirow[b]{2}{*}{$P$ value } \\
\hline & & Mean & Std. Deviation & \\
\hline \multicolumn{5}{|l|}{ Sex } \\
\hline Male & $60(70.51$ & 31.13 & 6.74 & \multirow{2}{*}{0.31} \\
\hline Female & $25(29.41)$ & 30.08 & 6.93 & \\
\hline \multicolumn{5}{|l|}{ Mode of Trauma } \\
\hline Fall from height & 41(48.24) & 20.08 & 12.03 & \multirow{3}{*}{0.35} \\
\hline MVA & $34(40.00)$ & 21.94 & 10.91 & \\
\hline Others & 10(11.76) & 17.83 & 8.93 & \\
\hline \multicolumn{5}{|l|}{ Native Area } \\
\hline Rural & $46(54.12)$ & 19.78 & 10.39 & \multirow{3}{*}{0.64} \\
\hline Urban & $39(45.88)$ & 21.47 & 12.21 & \\
\hline \multicolumn{4}{|l|}{ Injury Type } & \\
\hline ASIA-A & 28(32.94) & 21.16 & 11.30 & \multirow{3}{*}{0.77} \\
\hline ASIA-B/C/D & 33(38.82) & 19.57 & 11.63 & \\
\hline ASIA-E & $24(28.24)$ & 21.22 & 10.94 & \\
\hline \multicolumn{5}{|l|}{ Level of Injury } \\
\hline Dorsal & 16(18.82) & 19.74 & 10.41 & \multirow{3}{*}{0.86} \\
\hline Dorso-Lumbar & $52(61.18)$ & 20.80 & 11.20 & \\
\hline Lumbar & $17(20.00)$ & 20.59 & 12.62 & \\
\hline
\end{tabular}

TABLE 2: Demographic and clinical characteristics of patients

ASIA: American Spinal Cord Injury Association, MVA: Motor Vehicular Accident

Vitamin D level on the fifth day of injury was maximum (mean $25.7143 \pm 8.32 \mathrm{ng} / \mathrm{ml}$ ), but it was also insignificant (Table 3).

\begin{tabular}{|c|c|c|c|}
\hline \multirow{2}{*}{ Duration of injury (in days) } & \multicolumn{2}{|c|}{ Vitamin D levels (in ng/ml) } & \multirow{2}{*}{$P$ value } \\
\hline & Mean & Std. Deviation & \\
\hline 1 & 19.5179 & 10.10567 & \multirow{7}{*}{0.27} \\
\hline 2 & 22.4440 & 12.31114 & \\
\hline 3 & 21.8929 & 12.58763 & \\
\hline 4 & 13.1000 & 11.72035 & \\
\hline 5 & 25.7143 & 8.32275 & \\
\hline 6 & 16.1333 & 5.27289 & \\
\hline 7 & 13.2000 & . & \\
\hline
\end{tabular}

TABLE 3: Vitamin D levels in subjects with respect to duration of injury

Mean vitamin D level of subjects with samples taken during the summer season was $23.67 \pm 12.15 \mathrm{ng} / \mathrm{ml}$. It 


\section{Cureus}

was higher and significant compared to mean vitamin D level of subjects with samples taken during the winter season $(16.5189 \pm 8.45 \mathrm{ng} / \mathrm{ml})$ (Table 4, Figure 2).

\begin{tabular}{|c|c|c|c|}
\hline \multirow{2}{*}{ Season } & \multicolumn{2}{|c|}{ Vitamin D levels (in ng/ml) } & \multirow{2}{*}{ P-value } \\
\hline & Mean & Std. Deviation & \\
\hline WINTER & 16.5189 & 8.45290 & \multirow{2}{*}{0.003} \\
\hline SUMMER & 23.6708 & 12.15298 & \\
\hline
\end{tabular}

TABLE 4: Vitamin D levels in subjects with relation to the seasonal presentation

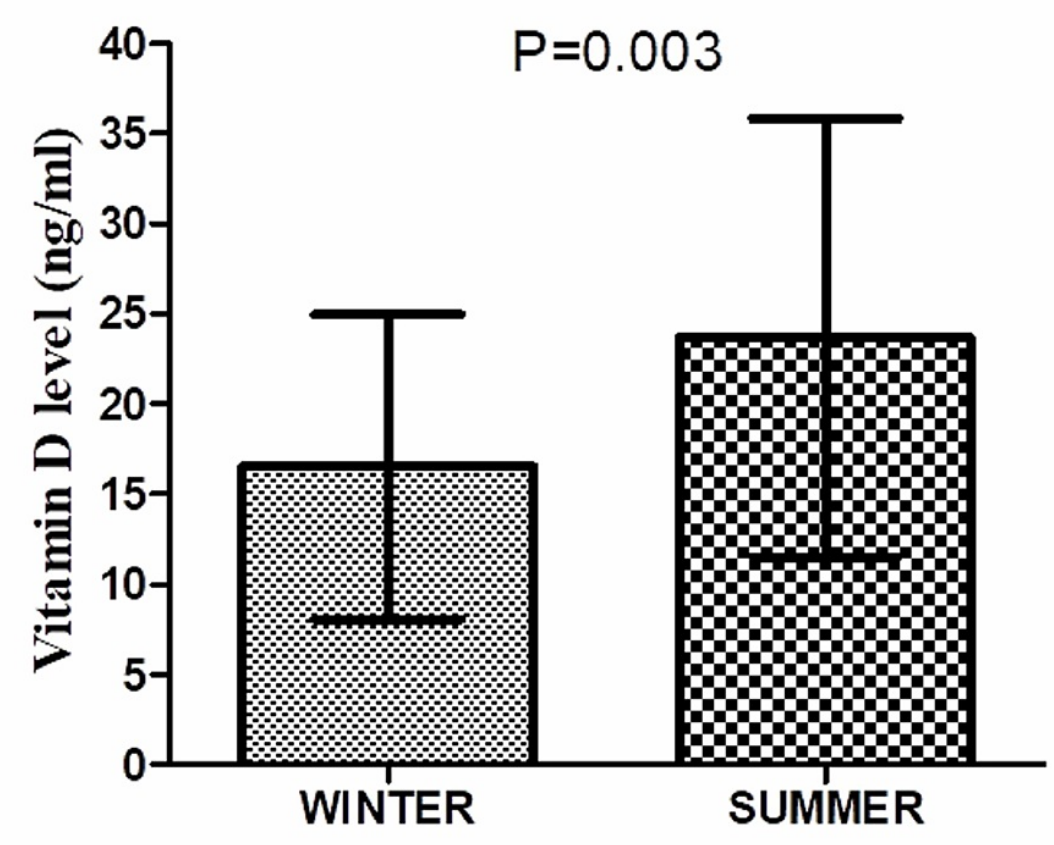

FIGURE 2: Vitamin D level variation with season

\section{Discussion}

This study describes the prevalence of vitamin D deficiency in ASCI patients presenting within a week of the injury. We found that in our study population almost 76.5\% (65/85) cases had either insufficient levels or deficient levels of serum vitamin D. The observed low level of 25(OH) vitamin D3 may also be due to acute systemic inflammatory response to spinal trauma that can result in a decrease in vitamin D binding protein and subsequently decreases $25(\mathrm{OH})$ vitamin D3 levels [10]. However, we did not observe any significant association between vitamin $\mathrm{D}$ levels and the duration of the injury. Future studies with serial measurement of vitamin D binding protein and 25(OH) vitamin D3 level in cases of ASCI will probably answer this question and help us to better understand the exact cause of vitamin D deficiency in this cohort.

In our study, $76.5 \%$ of patients had vitamin D levels below $30 \mathrm{ng} / \mathrm{ml}$ and the mean $25(\mathrm{OH})$ vitamin D3 level was $20.56 \pm 11.22 \mathrm{ng} / \mathrm{ml}$. Nemunaitis et al. [11] observed a 93\% prevalence of vitamin D deficiency in his study on 100 spinal cord injury patients, which included acute, subacute and chronic SCI patients with a mean $25(\mathrm{OH})$ vitamin D3 level of $16.29 \pm 7.73 \mathrm{ng} / \mathrm{ml}$. Further, in their study, there were 45 patients with a duration of injury less than one month and they had a mean serum level of $14.5 \pm 7.0 \mathrm{ng} / \mathrm{ml}$.

We did not find any significant relation in vitamin $\mathrm{D}$ levels amongst the cases presenting to us on the day of the injury and those presenting on the seventh day after the injury, nor did we find any correlation between demographic details, mode of trauma, level of injury, or neurological status in our cases. Nemunaitis et al. [11] had similar observations on these criteria in their study. 
In our study, seasonal variations were found to have an influence on vitamin D levels. The patients who were admitted in the summer season had a higher level of vitamin D as compared to those admitted in the winter season. Oleson et al. [12] found that $25(\mathrm{OH})$ vitamin D3 levels were less than $32 \mathrm{ng} / \mathrm{mL}$ in $65 \%$ of ASCI patients who present with injury in the summer season, whereas this figure was $84 \%$ in cases of ASCI presenting in the winter season. They observed a mean $25(\mathrm{OH})$ vitamin D3 level of $28.03 \pm 15.25 \mathrm{ng} / \mathrm{ml}$ in ASCI during the summer season and $21.72 \pm 12.56 \mathrm{ng} / \mathrm{ml}$ in ASCI winter season. In our series, vitamin D level was $23.67 \pm 12.15 \mathrm{ng} / \mathrm{ml}$ in cases of ASCI admitted during the summer season and $16.51 \pm 8.45 \mathrm{ng} / \mathrm{ml} \mathrm{during}$ the winter season.

Our study was done in patients belonging to the northern part of the country with $26^{\circ}$ latitude. In winters, sunlight is not optimal to synthesize vitamin D. We observed a low level of vitamin D in the winter in our subjects, correlating with other previous studies $[13,14]$ done at the same geographical area in a different cohort of patients. Our study is probably one of the first to report the prevalence of vitamin D deficiency in ASCI at the time of admission in our region.

In one of the animal studies available in the literature, supplementing vitamin D in the setting of ASCI with neurological deficit within a week of injury was associated with neurological recovery [15]. We also had $76.5 \%$ of cases in our study with vitamin D deficiency, thus an early diagnosis and supplementation with vitamin D might also be helpful for neurological recovery in such cases. A detailed study in the future might provide us with a better insight into this aspect of treatment.

The major limitation of our study is that it was not possible for us to ascertain the prior status of vitamin D levels in cases presenting to us with SCI. In any case, decreased levels of vitamin D if diagnosed in time, especially in such cases, will definitely help in decreasing complications and managing these cases more efficiently. Another limitation is that we did not enquire about the dietary details of patients and sun exposure that may impact the analysis and give insight regarding vitamin D status before the injury. We did not take ethnic and racial factors into account in our study, which have been reported as significant in previous studies $[11,12]$. A prospective study with a larger sample size and evaluation of vitamin $\mathrm{D}$ levels over a longer period of time post-injury and correlating it with the neurological recovery pattern will help us gain further information which could guide us for future research plans. Multi-centre studies with a larger sample size are required to elaborate on the epidemiology of vitamin D deficiency in ASCI patients. We took a cut-off value of $20 \mathrm{ng} / \mathrm{ml}$ as a deficiency state and between $21-30 \mathrm{ng} / \mathrm{ml}$ as an insufficiency state [9]; however, these levels are variable in the literature [5,7] and they vary according to the race and region as well. Thus, to have standard cut-off values with respect to the population being studied becomes important to diagnose and classify vitamin D deficiency status in ASCI cases. Further studies can be undertaken to generate robust data to formulate guidelines regarding diagnostic cut-off values of $25(\mathrm{OH})$ vitamin D3 level in ASCI patients.

\section{Conclusions}

Vitamin D deficiency was significantly prevalent in ASCI patients admitted to our hospital. $76.5 \%$ of patients had vitamin D levels below $30 \mathrm{ng} / \mathrm{ml}$ in our study. Routine measurement of $25(\mathrm{OH})$ vitamin D3 levels at the time of admission is recommended for early diagnosis of vitamin D deficiency. Early treatment will be helpful in the prevention of osteoporosis and its related consequences in the long term. Future studies are warranted to investigate the role of early vitamin D supplementation in neurological recovery from spinal cord injury.

\section{Additional Information \\ Disclosures}

Human subjects: Consent was obtained or waived by all participants in this study. King George's Medical University, Institutional Ethics Committee issued approval IEC number: 95th ECM II A/P5. EC decision: Approved. Animal subjects: All authors have confirmed that this study did not involve animal subjects or tissue. Conflicts of interest: In compliance with the ICMJE uniform disclosure form, all authors declare the following: Payment/services info: All authors have declared that no financial support was received from any organization for the submitted work. Financial relationships: All authors have declared that they have no financial relationships at present or within the previous three years with any organizations that might have an interest in the submitted work. Other relationships: All authors have declared that there are no other relationships or activities that could appear to have influenced the submitted work.

\section{References}

1. Chabas JF, Stephan D, Marqueste T, et al.: Cholecalciferol (vitamin D3) improves myelination and recovery after nerve injury. PLoS ONE. 2013, 8:65034. 10.1371/journal.pone.0065034

2. Faye P, Poumeaud F, Miressi F, et al.: Focus on 1,25-dihydroxy vitamin D3 in the peripheral nervous system . Front Neurosci. 2019, 13:348. 10.3389/fnins.2019.00348

3. Szabo A: Skeletal and extraskeletal consequences of vitamin D deficiency . Orv Hetil. 2011, 152:1312-1319. 10.1556/oh.2011.29186

4. Christakos S, Hewison M, Gardner DG, et al.: Vitamin D: beyond bone. Ann NY Acad Sci. 2013, 1287:45-58. 


\section{Cureus}

$10.1111 /$ nyas. 12129

5. Lamarche J, Mailhot G: Vitamin D and spinal cord injury: should we care? . Spinal Cord. 2016, 54:1060-1075. 10.1038/sc.2016.131

6. Lazo MG, Shirazi P, Sam M, Giobbie-Hurder A, Blacconiere MJ, Muppidi M: Osteoporosis and risk of fracture in men with spinal cord injury. Spinal Cord. 2001, 39:208. 10.1038/sj.sc.3101139

7. Flueck JL, Perret C: Vitamin D deficiency in individuals with a spinal cord injury: a literature review . Spinal Cord. 2017, 55:428-434. 10.1038/sc.2016.155

8. Van Middendorp JJ, Goss B, Urquhart S, Atresh S, Williams RP, Schuetz M: Diagnosis and prognosis of traumatic spinal cord injury. Global Spine J. 2011, 1:1-8. 10.1055/s-0031-1296049

9. Holick MF, Binkley NC, Bischoff-Ferrari HA, et al.: Evaluation, treatment and prevention of vitamin D deficiency: an Endocrine Society practice guideline. J Clin Endocrinol Metab. 2011, 96:1911-30. 10.1210/jc.2011-0385

10. Waldron JL, Ashby HL, Cornes MP, et al.: Vitamin D: a negative acute phase reactant . J Clin Pathol. 2013, 66:620-622. 10.1136/jclinpath-2012-201301

11. Nemunaitis GA, Mejia M, Nagy JA, Johnson T, Chae J, Roach MJ: A descriptive study on vitamin D levels in individuals with spinal cord injury in an acute inpatient rehabilitation setting. PM R. 2010, 2:202-208. 10.1016/j.pmrj.2010.01.010

12. Oleson CV, Patel PH, Wuermser LA: Influence of season, ethnicity, and chronicity on vitamin D deficiency in traumatic spinal cord injury. J Spinal Cord Med. 2010, 33:202-213. 10.1080/10790268.2010.11689697

13. Sahu M, Bhatia V, Aggarwal A, Rawat V, Saxena P, Pandey A, Das V: Vitamin D deficiency in rural girls and pregnant women despite abundant sunshine in northern India. Clin Endocrinol. 2009, 70:680-4.

10.1111/j.1365-2265.2008.03360.x

14. Balasubramanian K, Rajeswari J, Gulab, Govil YC, Agarwal AK, Kumar A, Bhatia V: Varying role of vitamin D deficiency in the etiology of rickets in young children vs. adolescents in northern India. J Trop Pediatr. 2013, 49:201-206. 10.1093/tropej/49.4.201

15. Féron F, Marqueste T, Bianco J, Gueye Y, Chabas JF, Decherchi P: Repairing the spinal cord with vitamin D: a promising strategy. Biol Aujourdhui. 2014, 208:69-75. 10.1051/jbio/2014008 